\title{
Revascularization for Complex Cerebral Aneurysms
}

\author{
Bai-Nan Xu, Zheng-Hui Sun, Chen Wu, Jin-Li Jiang, Ding-Biao Zhou, \\ Xin-Guang Yu, Garnette R. Sutherland, Bao-Min Li
}

\begin{abstract}
Background and Purpose: Complex cerebral aneurysms may require indirect treatment with revascularization. This manuscript describes various surgical revascularization techniques together with clinical outcomes. Methods: Thirty-two consecutive patients with complex cerebral aneurysm were managed from November 2005 to October 2008 . Techniques used for revascularization were high-flow bypass, low-flow bypass, branch artery reimplantion, and primary reanastomosis. Physiologic and anatomic monitoring technologies, including electroencephalography, somatosensory evoked potential monitoring, microvascular doppler ultrasonography, and/or indocyanine green videoangiography were used intraoperatively to assess both brain physiology and vascular anatomy. Patient outcome was determined using the Glasgow Outcome Scale at discharge and at a mean of 12 months post operation (range 6-25 months). Results: Two cervical carotid aneurysms (6\%) were resected followed by primary reanastomosis, 21 aneurysms (66\%) were trapped following saphenous vein high-flow bypasses, five (16\%) were clipped after superficial temporal or occipital artery low-flow bypasses, and four (12\%) middle cerebral branch arteries were reimplanted. Of the 32 patients at discharge, $29(91 \%)$ had a Glasgow Outcome Scale of four or five, two $(6 \%)$ had severe disability, and one $(3 \%)$ died. Conclusion: Cerebral revascularization remains an effective and reliable procedure for treatment of complex cerebral aneurysms. Low morbidity and mortality rates reflect the maturity of patient selection and surgical technique in the management of these lesions.
\end{abstract}

RÉSUMÉ: Revascularisation des anévrismes cérébraux complexes. Contexte et objectif : Il faut parfois avoir recours au traitement indirect avec revascularisation dans les cas d'anévrismes cérébraux complexes. Cet article décrit les différentes techniques chirurgicales de revascularisation ainsi que leurs résultats cliniques. Méthode : Trente-deux patients consécutifs atteints d'anévrismes cérébraux complexes ont été traités entre novembre 2005 et octobre 2008. Les techniques suivantes de revascularisation ont été utilisées : pontage à haut débit, pontage à bas débit, réimplantation d'une branche artérielle et réanastomose primaire. Les techniques suivantes de surveillance physiologique et anatomique ont été utilisées pendant l'intervention pour étudier la physiologie cérébrale et l'anatomie vasculaire : l'électroencéphalographie, la surveillance des potentiels évoqués somesthésiques, l'échographie doppler microvasculaire et/ou la vidéoangiographie au vert d'indocyanine. Les résultats ont été évalués chez les patients au moyen de la Glasgow Outcome Scale au moment du congé hospitalier et de nouveau en moyenne 12 mois après la chirurgie (écart de 6 à 25 mois). Résultats : Deux anévrismes de la carotide externe (6\%) ont été excisés avec réanastomose primaire de l'artère, 21 anévrismes (66\%) ont été séquestrés après un pontage de haut débit au moyen de la veine saphène, 5 anévrismes (16\%) ont été traités par un pontage de bas débit au moyen de l'artère temporale superficielle ou de l'artère occipitale puis d'un clip et 4 (12\%) branches de l'artère cérébrale moyenne ont été réimplantées. Parmi les 32 patients, 29 (91\%) avaient un score de 4 ou 5 à la Glasgow Outcome Scale au moment du congé hospitalier, $2(6 \%)$ avaient une invalidité sévère et 1 patient (3\%) est décédé. Conclusion : La revascularisation cérébrale demeure une intervention efficace et fiable pour traiter les anévrismes cérébraux complexes. Les faibles taux de morbidité et de mortalité reflètent l'expérience acquise au cours des années dans la sélection des patients et des techniques chirurgicales utilisées pour traiter ces lésions.

Can. J. Neurol. Sci. 2011; 38: 712-718

Cerebral aneurysms are commonly managed by isolating the aneurysm from the cerebral circulation using either direct clipping or endovascular techniques. These procedures are frequently not suitable for complex aneurysms due to size, morphology, location, or wall characteristics such as intramural thrombus, atherosclerosis, calcification, and/or dissection..$^{1-4}$ Some aneurysms are less accessible to direct surgical treatment, in particular those located in the petrous, intracavernous, or paraclinoid internal carotid artery (ICA). Posterior circulation aneurysms, especially basilar trunk aneurysms, are particularly challenging, due to their deep-seated location and adjacent neurovascular structures. ${ }^{5-9}$ Although skull base techniques provide potential approaches to these lesions, direct surgical intervention is often associated with high morbidity and mortality.$^{10}$ When the base of the aneurysm is severely calcified or atherosclerotic, ischemic infarction may occur due to parent artery occlusion or embolism to the distal branches." For traumatic false aneurysms with no consistent aneurysm wall,

From the Department of Neurosurgery (B-NX, Z-HS, CW, J-LJ, D-BZ, X-GY, B-ML), General Hospital of Chinese People's Liberation Army, Beijing, China; Department of Clinical Neurosciences (GRS), University of Calgary, Calgary, Alberta, Canada. Received December 7, 2010. Final Revisions SubmitTed May 2, 2011. Correspondence to: Bai-Nan Xu, Department of Neurosurgery, General Hospital of Chinese People's Liberation Army, 28 Fuxing Rd, Haidian District, 100853, Beijing, China. 
clipping may not be feasible, and trapping is often the preferred procedure. $^{12}$

Despite rapid progress in endovascular aneurysm treatment with balloon or stent-assisted techniques, ${ }^{13-15}$ difficulties remain in managing aneurysms that are wide-necked, large and giant, small and blister-like, fusiform and semi-fusiform, dolichoectatic, dissecting, or those involving parent or perforating arteries.,13,16-22 Such complex aneurysms may, in some cases, be safely treated indirectly, with or without revascularization..$^{3,21,23}$ This manuscript reports on surgical approaches using various intraoperative physiological and vascular monitoring techniques, together with associated clinical outcome from the operative management of 32 consecutive patients with complex cerebral aneurysms.

\section{METHODS}

\section{Patient population}

This series included 32 patients with 34 aneurysms, representing $7 \%$ of the 486 patients with cerebral aneurysms treated between November 2005 and October 2008 at the Department of Neurosurgery, General Hospital of Chinese People's Liberation Army, Beijing, China. Of the 32 patients, 19 were female $(60 \%)$ and 13 were male $(40 \%)$; mean age was 51 years (range 22-65). Eleven patients (34\%) had ruptured aneurysms, six (18\%) had impaired visual acuity or visual field deficit, and four (12\%) had oculomotor nerve palsy (Table). Two (6\%) patients presented with a pulsating neck mass. Other presentations included retro-orbital pain, hemiparesis, headache, dizziness, dysphagia, and diplopia. Two aneurysms were found incidentally. All patients were in good clinical condition before the operation, with a Hunt and Hess grade of I or II. ${ }^{18}$

Digital subtraction angiography detected 34 aneurysms; 11 aneurysms were giant, 18 were large, and three were mediumsized. In the two patients with more than one aneurysm, the second was located at the anterior communicating artery complex or internal carotid artery bifurcation.

All patients underwent a preoperative balloon test occlusion, during which an interval of hypotension was induced. Vertebral injection with common carotid artery compression in the neck was used to evaluate collateral circulation through the posterior communicating artery when indicated. 5,17

\section{Surgical technique}

\section{i. High-flow bypass}

This procedure was performed on 21 patients who failed the balloon test occlusion (Table). The extracranial carotid bifurcation was exposed through a standard neck dissection and the middle cerebral artery M2 segments through a frontal temporal craniotomy. The saphenous vein was harvested and end-to-side anastomosis performed, first to the temporal M2 segment and then to the external carotid artery. The procedure was completed by trapping the aneurysm or Hunterian ligation of the parent artery ${ }^{5,24}$ (Figure 1; Video 1 on-line at www.cjns.org).

\section{ii. Low-flow bypass}

In those cases (five patients) when the artery distal to the aneurysm could not be preserved, low-flow bypass revascularization was used to augment cerebral blood flow (Table). For the bypass, the superficial temporal artery or occipital artery were dissected, ligated and prepared for end-toside anastomosis to a branch of the middle cerebral artery, posterior cerebral artery, or posterior inferior cerebellar artery (Figure 2; Video 2 on-line).

\section{iii. Aneurysm excision with primary reanastomosis or reimplantation}

Following aneurysm resection, end-to-end anastomosis of the parent artery was performed in two patients. In those cases (four patients) when the distal branch arose from the aneurysm, it was reimplanted (Figure 3; Video 3 on-line; Table).

During temporary occlusion of the recipient artery, intraoperative electroencephalography and somatosensory evoked potential monitoring were routinely used to detect ischemic induced electrophysiological changes. Intraoperative microvascular doppler ultrasonography was used to assess blood flow in parent and branch arteries. For the last nine cases, intraoperative indocyanine green videoangiography identified patency of the bypass graft, distal branches, and perforating arteries.

Postoperative digital subtraction angiography or computed tomogram (CT) angiography were performed to confirm aneurysm obliteration and graft patency. The patients were

Table: Comparison of treatment method versus presentation and aneurysm type

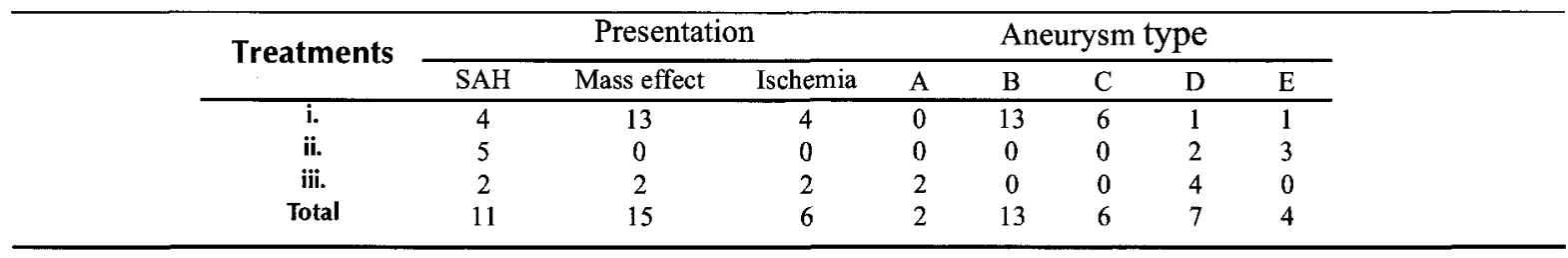

i. High-flow bypass; ii. Low-flow bypass; iii. Aneurysm excision with primary reanastomosis or reimplantation;

A: Cervical internal carotid artery (ICA); B: Cavernous ICA; C: Paraclinoid and supraclinoid ICA; D: Middle cerebral artery;

E: Posterior circulation 


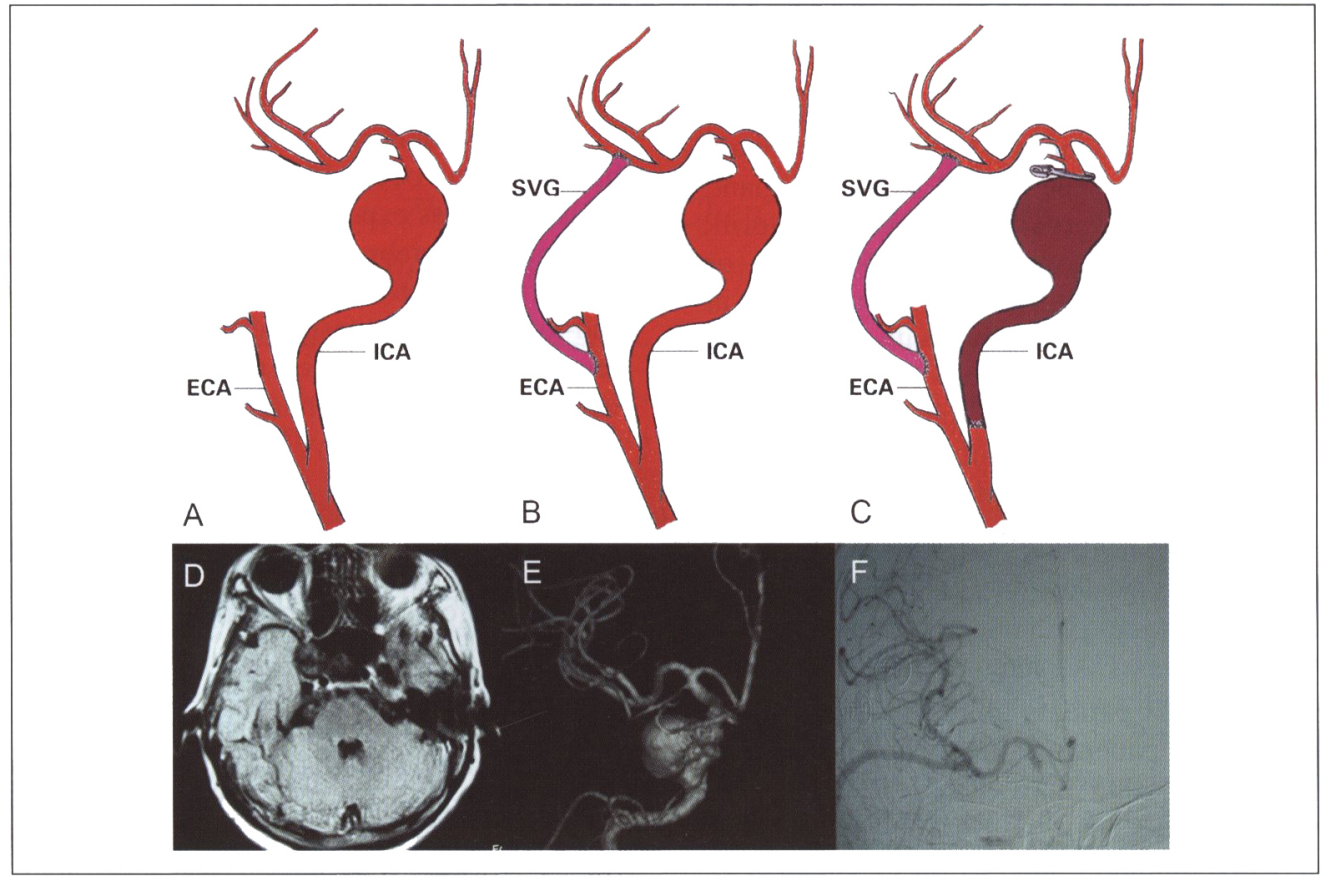

Figure 1: Patient 1. Illustration of a large intracavernous aneurysm. A, B, C: Schematic illustration of the procedure. D: Preoperative MRI showing a right intracavernous ICA aneurysm. E: Preoperative $3 D$ digital subtraction angiography showing an intracavernous aneurysm. $F$ : Postoperative digital subtraction angiography showing a patent bypass vessel and no aneurysm.

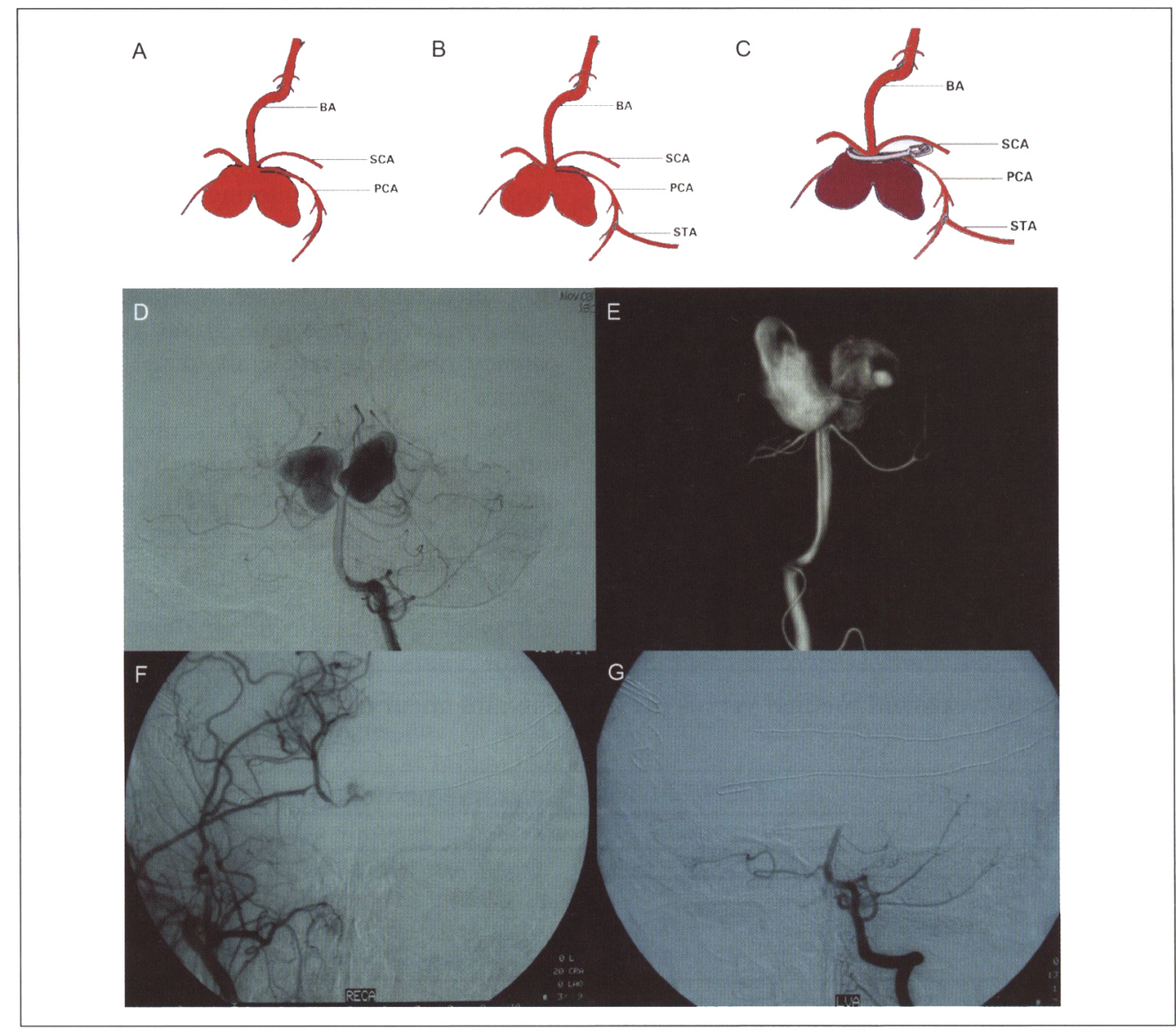

Figure 2: Patient 2. Illustration of basilar bifurcation aneurysm. A, B, C: Schematic illustration of the procedure. D, E: Preoperative angiogram and 3D-DSA showing a lobulated giant basilar bifurcation aneurysm. F: Postoperative DSA showing the patency of STA and PCA. G: Left vertebral angiogram showing no flow within the aneurysm. 


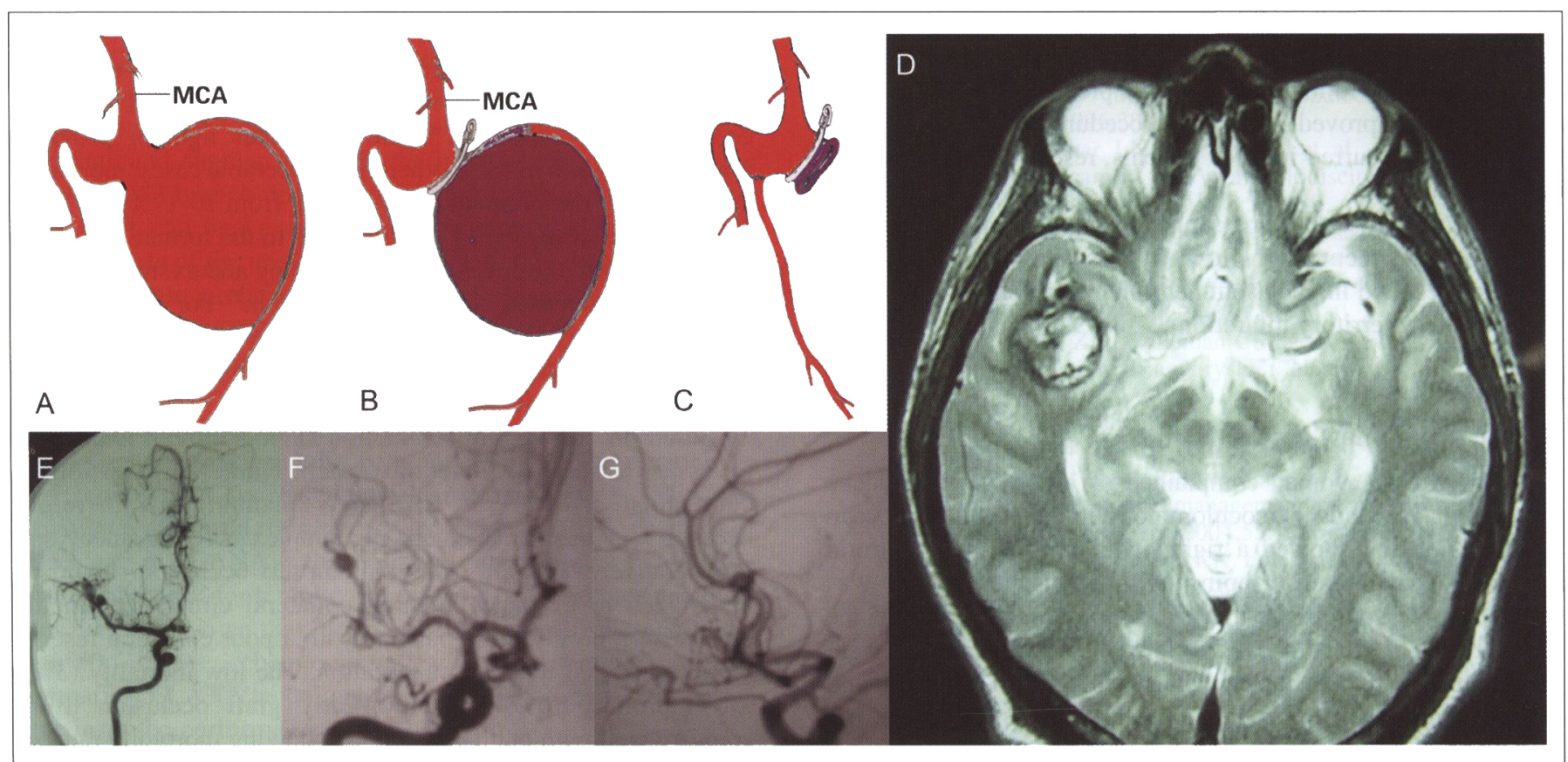

Figure 3: Patient 3. Illustration of a giant MCA aneurysm with thrombus. A, B, C: Schematic illustration of the procedure. D: Preoperative MRI showing a large middle cerebral artery with thrombus. E: Preoperative anteroposterior contrast angiogram showing enlargement of the MCA bifurcation and inflow orifice of the aneurysm. The distal branches were compressed without good visualization. $F, G$ : Postoperative anteroposterior and lateral view angiogram revealed that there was a residual enlarged bifurcation, and the distal branch had good visualization.

clinically evaluated at discharge and at a mean follow up time of 12 months (range 6-25 months).

\section{RESULTS}

\section{Revascularization techniques}

Nineteen aneurysms (59\%) were trapped following high-flow bypass. Two aneurysms $(6 \%)$ had proximal occlusion of the parent artery following the high-flow bypass procedure. Five $(16 \%)$ aneurysms were trapped or had parent arteries occluded after a low-flow bypass procedure. Four (12\%) middle cerebral branch arteries were reimplanted. One giant cervical internal carotid artery aneurysm was resected and the carotid artery reconstructed using a saphenous vein interpositional graft. In another patient with a giant cervical internal carotid aneurysm, a primary carotid-to-carotid anastomosis was performed following resection of the aneurysm (Table). In the two patients with more than one aneurysm, the second aneurysm was surgically dissected and clipped. Temporary occlusion time in anastomosis procedures averaged $42 \mathrm{~min}$ (range $35-50 \mathrm{~min}$ ).

\section{Postoperative vascular imaging}

Twenty of the 21 patients who underwent high-flow bypass procedures demonstrated graft patency with no residual aneurysm. In one patient, saphenous vein graft occlusion was observed. Residual aneurysm was evident in two patients. One of these residual aneurysms enlarged six months postoperatively without rebleeding, and the other was thrombosed on subsequent digital subtraction angiography follow up.

\section{Clinical outcome}

A single perioperative mortality occurred in a 61-year-old man with a giant basilar trunk thrombotic aneurysm, measuring $37 \mathrm{~mm}$ in diameter. The patient presented with symptoms of brain stem compression and multiple cranial nerve palsies. Preoperatively, collateral flow was investigated with carotid compression during vertebral artery contrast injection, revealing poor collateral flow through the posterior communicating arteries. The non-dominant vertebral artery was occluded by placing a detachable balloon distal to the origin of the posterior inferior cerebellar artery to reduce flow to the aneurysm. The symptoms resolved, but recurred two days later. Seven days later, the patient was brought to surgery, where the external carotid artery was anastomosed to the posterior cerebral artery P2 segment, using an interposition saphenous vein graft. Immediately after the bypass procedure, the dominant vertebral artery was also occluded by a detachable balloon during which the bypass graft was confirmed patent. The patient did not awaken. Computed tomogram imaging showed changes consistent with brain stem and ipsilateral occipital lobe infarction. A decompressive temporal-occipital craniectomy was performed and hypertensive therapy was implemented to increase perfusion pressure. The patient died five days after the operation, secondary to brain stem infarction.

The 31 remaining patients were followed and examined at an average of 12 months postoperatively (range 6-25 months). At discharge, the Glasgow Outcome Scale score ${ }^{13}$ was five in 20 patients, four in nine patients, and three in two patients. At follow up, the Glasgow Outcome Scale score was five in 22 
patients, four in seven patients and three in two patients. Five of six patients with preoperative visual disturbances showed improvement on follow up. All four preoperative oculomotor nerve palsies improved. Transient procedure-related oculomotor nerve palsies occurred in three patients, resolving by the follow up examination.

In one patient undergoing saphenous vein to middle cerebral artery M2 segment high-flow bypass, postoperative graft occlusion resulted in persistent hemiplegia, secondary to middle cerebral artery territory infarction.

\section{Illustrative cases}

Patient 1: High-flow bypass.

A 65-year-old woman complained of intermittent headache and diplopia, secondary to oculomotor nerve palsy, for one year. Vascular imaging showed a right giant intracavernous carotid aneurysm. Aneurysm trapping with revascularization was selected as the appropriate treatment modality. Exposure of the cervical carotid artery and a frontal-temporal craniotomy were performed. The middle cerebral artery temporal M2 segment and external carotid artery were anastomosed using a saphenous vein graft. The aneurysm was then trapped between the cervical internal carotid artery and the supraclinoid internal carotid artery, proximal to the origin of the posterior communicating artery. Postoperatively, the patient improved with resolution of her headache and slow progressive reduction in her oculomotor nerve palsy (Figure 1; Video 1 on-line).

\section{Patient 2: Low-flow bypass.}

A 54-year-old woman with a two months history of unsteady gait presented with sudden headache. Digital subtraction angiography revealed a lobulated giant basilar bifurcation aneurysm. The patient underwent a left subtemporal craniotomy. The superficial temporal artery was anastomosed to the posterior cerebral artery P2 segment in an end-to-side fashion. The basilar artery was then occluded with a clip, placed between the posterior cerebral and the superior cerebellar arteries. The contralateral posterior cerebral artery continued to be supplied by a patent posterior communicating artery. Post-operative digital subtraction angiography showed thrombosis of the aneurysm and graft patency. (Figure 2; Video 2 on-line).

\section{Patient 3: Aneurysm excision with reimplantation.}

A 45-year-old man presented with dizziness for one month. Preoperative MRI showed a large partially-thrombosed right middle cerebral aneurysm. Digital subtraction angiography revealed an enlargement of the middle cerebral artery bifurcation with a wide-necked aneurysm. The distal branches were compressed and poorly visualized. Following surgical exposure, the aneurysm was incised and thrombus evacuated. The redundant aneurysm wall was resected, and a branch arising from the base of the aneurysm was reimplanted into the enlarged bifurcation. Postoperatively, the patient had no neurological deficit. Digital subtraction angiography showed residual enlarged bifurcation, with the reimplanted distal branch well visualized. (Figure 3; Video S3 on-line).

\section{Discussion}

Proximal Hunterian ligation of a major cerebral vessel is a well established indirect method for the treatment of giant cerebral aneurysms. ${ }^{9,17,24}$ While Hunterian ligation provides reasonable results in these otherwise inoperable cases, morbidity and mortality rates remain high, ranging from $10-17 \% .25,26 \mathrm{Such}$ a therapeutic strategy may also give rise to the formation of new aneurysms or to the enlargement of existing aneurysms along the pathway of increased collateral circulation. ${ }^{27}$ For patients with complex aneurysms that have marginal or low collateral potential, an extracranial-to-intracranial bypass provides an alternative treatment strategy.

Based on only digital subtraction angiography, it is difficult to assess collateral potential when Hunterian ligation is contemplated. ${ }^{12,13,16,22,28}$ Extensive planning is therefore necessary in the management of complex cerebral aneurysm. Preoperative evaluation using balloon test occlusion should be undertaken to evaluate potential collateral circulation. In the present series, only those patients with a poor collateral reserve were considered for revascularization. The low mortality (3\%), low morbidity $(6 \%)$, and low early graft occlusion (3\%), compare well with published reports showing morbidity rates of $6-16 \%$, mortality rates of $2-12 \%$, early graft occlusion rates of 1.3- $29 \%$, and late graft occlusion rates of $0-4 \% .^{7-9,14,17,21,29-31}$

Notwithstanding the widespread application of endovascular techniques for the management of small to medium-sized aneurysms, endovascular strategies have also evolved for large and giant aneurysms. ${ }^{32-34}$ Covered stents have been used to occlude parent vessels and to treat carotid-cavernous fistulas, carotid blowout syndrome and fusiform dissecting aneurysm of the vertebral artery while preserving vessel patency. The main technical limitations associated with the placement of covered stents are their limited longitudinal flexibility and occlusion of side branches with potential ischemic injury. ${ }^{33}$ To overcome these limitations, flexible porous stents have been developed, allowing for more accurate placement and preservation of blood flow through side branches. ${ }^{35}$ In addition, the flexible stent may aid packing of the aneurysm with coils by acting as a rigid scaffold, preventing coil herniation into the parent vessel. Shortterm results from a multi-centre registry of 141 patients showed an inability to place the stent in $3 \%$, inaccurate stent deployment in $2 \%, 6 \%$ of patients had temporary neurological deficit while $3 \%$ permanent and $2 \%$ mortality ${ }^{35}$ Furthermore, for giant aneurysms, mass effect may not be relieved by stent-assisted packing. The recent development of a flow-diverting stent has shown considerable promise in the treatment of complex aneurysms. ${ }^{36}$ Redirecting the blood flow away from the aneurysm orifice may result in thrombosis within the aneurysm or prevent further enlargement. While these technologies represent remarkable advances, significant delayed complications have now been reported, including stent thrombosis. ${ }^{37}$ Further technical limitations of stent placement include the risk of vasospasm, vessel injury with intimal dissection vessel stenosis, or occlusion. ${ }^{33}$ Anatomic tortuosity may also preclude optimal stent deployment. Therefore at present, surgery remains a viable and often preferable alternative to such approaches, particularly given the lack of information regarding long-term outcome. 
An important task in cerebral revascularization is the choice of recipient artery. The middle cerebral artery temporal M2 segment was routinely selected as the recipient, rather than the bifurcation itself ${ }^{23}$ as it supplies only the temporal, temporaloccipital, and angular areas. Furthermore, the orientation of the temporal M2 branch relative to the distal end of the saphenous vein graft can make suture manipulation easier. ${ }^{20}$ The low ischemic rate of the present study suggests that these regions are able to tolerate a relatively long interval of ischemia. QuinonesHinojosa et al suggested that anastomosis time should be less than 45 minutes, preferably less than 30 minutes. ${ }^{21}$ Consistent with this, the temporary occlusion time in the present series averaged 42 minutes (range 35-50 minutes), and only one patient had a procedure-related postoperative ischemic complication.

Excimer laser-assisted nonocclusive anastomosis (ELANA) technique has been introduced over the past 15 years. The advantage of ELANA is the ability to perform revascularization without the need for temporary occlusion. ${ }^{38,39}$ The present study, however, has shown that, providing an anastomosis time is less than 40 minutes, ischemic complication is uncommon. A study comparing ELANA technique to conventional revascularization remains to be performed.

The single mortality in this series, a patient with a giant basilar trunk aneurysm, was treated with anastomosis between the external carotid artery and posterior cerebral artery P2 segment using the saphenous vein, followed by bilateral vertebral artery occlusion. Unfortunately, the posterior cerebral artery was sclerotic, limiting collateral blood flow. Likely, when flow was reestablished through the bypass, the reduced blood velocity allowed the aneurysm to thrombose and the perforating arteries to occlude, resulting in brain stem ischemia. Based on the literature ${ }^{30}$ and this outcome, it may be best to not occlude both vertebral arteries in giant basilar trunk aneurysms with poor collateral potential.

Several factors influence blood flow through the bypass, including the diameter of donor or recipient vessels, the size of anastomosis orifice, and the angle between donor and recipient vessels ${ }^{40}$ In this study, qualitative ultrasonography was used to detect blood flow and indocyanine green videoangiography was used to observe the vessel contour and patency. Physiological monitoring assures the surgeon during temporary vessel occlusion that sufficient blood flow to the distal brain is maintained through collateral networks. Evidence of ischemia could be managed by manipulating the collateral reserve through blood pressure elevation and hemodilution..$^{1,42}$

\section{CONCLuSions}

Cerebral revascularization is an effective and reliable procedure in the treatment of complex intracranial aneurysms. Despite successes with endovascular techniques and direct surgical clip occlusion, revascularization with indirect aneurysm management remains a viable treatment strategy. The middle cerebral artery M2 segment is an optimal recipient vessel. To limit mortality and morbidity rates related to these lesions, it is important that each case be evaluated by a multi-disciplinary group that includes individuals proficient in cerebral revascularization.

\section{REFERENCES}

1. Lawton MT, Hamilton MG, Morcos JJ, et al. Revascularization and aneurysm surgery: current techniques, indications, and outcome. Neurosurgery. 1996;38:83-92.

2. Linskey ME, Sekhar LN, Horton JA, et al. Aneurysms of the intracavernous carotid artery: a multidisciplinary approach to treatment. J Neurosurg. 1991;75:525-34.

3. Park EK, Ahn JS, Kwon do H, et al. Result of extracranialintracranial bypass surgery in the treatment of complex intracranial aneurysms: outcomes in 15 cases. J Korean Neurosurg Soc. 2008;44:228-33.

4. Surdell DL, Hage ZA, Eddleman CS, et al. Revascularization for complex intracranial aneurysms. Neurosurg Focus. 2008; 24:E21.

5. Drake CG. Giant intracranial aneurysms: experience with surgical treatment in 174 patients. Clin Neurosurg. 1979;26:12-95.

6. Evans JJ, Sekhar LN, Rak R, et al. Bypass grafting and revascularization in the management of posterior circulation aneurysms. Neurosurgery. 2004;55:1036-49.

7. Regli L, Piepgras DG, Hansen KK. Late patency of long saphenous vein bypass grafts to the anterior and posterior cerebral circulation. J Neurosurg. 1995;83:806-11.

8. Sekhar LN, Stimac D, Bakir A, et al. Reconstruction options for complex middle cerebral artery aneurysms. Neurosurgery. 2005; 56:66-74.

9. Steinberg GK, Drake CG, Peerless SJ, Deliberate basilar or vertebral artery occlusion in the treatment of intracranial aneurysms. Immediate results and long-term outcome in 201 patients. J Neurosurg. 1993;79:161-73.

10. Origitano TC, al-Mefty $O$, Leonetti JP, et al, Vascular considerations and complications in cranial base surgery. Neurosurgery. 1994;35:351-62.

11. Ohno $\mathrm{K}$, Arai $\mathrm{T}$, Isotani $\mathrm{E}$, et al. Ischaemic complication following obliteration of unruptured cerebral aneurysms with atherosclerotic or calcified neck. Acta Neurochir (Wien). 1999; 141:699-705.

12. Semple PL. Traumatic aneurysms. In: Le Roux PD, Winn HR Newell DW, editors. Management of cerebral aneurysms. Philadelphia, Pennsylvania. WB Saunders Co; 2004 . p. 397-407.

13. Ewald $\mathrm{CH}$, Kuhne D, Hassler WE. Bypass-surgery and coilembolisation in the treatment of cerebral giant aneurysms. Acta Neurochir (Wien). 2000;142:731-7.

14. Hacein-Bey L, Connolly ES, Jr, Mayer SA, et al. Complex intracranial aneurysms: combined operative and endovascular approaches. Neurosurgery. 1998;43:1304-12.

15. Lubicz B, Francois O, Levivier M, et al. Preliminary experience with the enterprise stent for endovascular treatment of complex intracranial aneurysms: Potential advantages and limiting characteristics. Neurosurgery. 2008;62:1063-9.

16. Anson JA, Stone JL, Crowell RM. Rupture of a giant carotid aneurysm after extracranial-to-intracranial bypass-surgery. Neurosurgery. 1991;28:142-7.

17. Drake CG, Peerless SJ, Ferguson GG. Hunterian proximal arterial occlusion for giant aneurysms of the carotid circulation. $J$ Neurosurg. 1994;81:656-65.

18. Hunt WE, Hess RM. Surgical risk as related to time of intervention in the repair of intracranial aneurysms. J Neurosurg. 1968;28: 14-20.

19. Jennett B, Bond M. Assessment of outcome after severe brain damage. Lancet. 1975;161:480-4.

20. Mohit AA, Sekhar LN, Natarajan SK, et al. High-flow bypass grafts in the management of complex intracranial aneurysms. Neurosurgery. 2007 Feb;60(2 Suppl 1):ONS105-22.

21. Quinones-Hinojosa A, Lawton MT. In situ bypass in the management of complex intracranial aneurysms: technique application in 13 patients. Neurosurgery. 2005;57:140-5.

22. Sanus GZ, Akar Z, Tanriverdi T, et al. Bypass to the intracranial giant or large internal carotid artery aneurysms: superficial temporal artery to middle cerebral artery bypass re-visited. Turk Neurosurg. 2007;17:60-5. 
23. Quinones-Hinojosa A, Du R, Lawton MT. Revascularization with saphenous vein bypasses for complex intracranial aneurysms. Skull Base. 2005;15:119-32.

24. Drake CG. Surgical treatment of ruptured aneurysms of the basilar artery. Experience with 14 cases. J Neurosurg. 1965;23:457-73.

25. Roski RA, Spetzler RF, Nulsen FE. Late complications of carotid ligation in the treatment of intracranial aneurysms. J Neurosurg. 1981;54:583-7.

26. Voris HC. Complications of ligation of the internal carotid artery. $J$ Neurosurg. 1951;8:119-31.

27. Miller CA, Hill SA, Hunt WE. "De novo" aneurysms: a clinical review. Surg Neurol. 1985;24: 173-80.

28. Field M, Jungreis CA, Chengelis N, et al. Symptomatic cavernous sinus aneurysms: management and outcome after carotid occlusion and selective cerebral revascularization. AJNR Am J Neuroradiol. 2003;24:1200-7.

29. Lawton MT, Spetzler RF. Surgical management of giant intracranial aneurysms: experience with 171 patients. Clin Neurosurg. 1995; 42:245-66.

30. Sekhar LN, Chandler JP, Alyono D. Saphenous vein graft reconstruction of an unclippable giant basilar artery aneurysm performed with the patient under deep hypothermic circulatory arrest: technical case report. Neurosurgery. 1998;42:667-72.

31. Sekhar LN, Duff JM, Kalavakonda C, et al. Cerebral revascularization using radial artery grafts for the treatment of complex intracranial aneurysms: techniques and outcomes for 17 patients. Neurosurgery. 2001;49:646-58.

32. Hoit DA, Schirmer CM, Malek AM. Stent graft treatment of cerebrovascular wall defects: intermediate-term clinical and angiographic results. Neurosurgery. 2008 May;62(5 Suppl 2): ONS380-8.

33. Lanzino G, Wakhloo AK, Fessler RD, et al. Efficacy and current limitations of intravascular stents for intracranial internal carotid, vertebral, and basilar artery aneurysms. J Neurosurg. 1999;91:538-46.
34. Burbelko MA, Dzyak LA, Zorin NA, et al. Stent-graft placement for wide-neck aneurysm of the vertebrobasilar junction. AJNR Am J Neuroradiol. 2004 Apr;25(4):608-10.

35. Mocco J, Snyder KV, Albuquerque FC, et al. Treatment of intracranial aneurysms with the Enterprise stent: a multicentre registry. J Neurosurg. 2009;110: 35-9.

36. Nelson PK, Lylyk P, Szikora I, et al. The pipeline embolization device for the intracranial treatment of aneurysms trial. AJNR Am J Neuroradiol. 2011;32:34-40.

37. Klisch J, Turk A, Turner R, et al. Very late thrombosis of Flowdiverting constructs after the treatment of large fusiform posterior circulation aneurysms. AJNR Am J Neuroradiol. 2011; 32:627-32.

38. Streefkerk HJ, Bremmer JP, van Weelden M, et al. The excimer laser-assisted nonocclusive anastomosis practice model: development and application of a tool for practicing microvascular anastomosis techniques. Neurosurgery. 2006 Feb; 58(1 Suppl):ONS148-56.

39. van Doormaal TP, van der Zwan A, Verweij BH, et al. Treatment of giant middle cerebral artery aneurysms with a flow replacement bypass using the excimer laser-assisted nonocclusive anastomosis technique. Neurosurgery. 2008;63:12-20.

40. Sekhar LN, Bucur SD, Bank WO, et al. Venous and arterial bypass grafts for difficult tumors, aneurysms, and occlusive vascular lesions: evolution of surgical treatment and improved graft results. Neurosurgery. 1999;44:1207-23.

41. Stead LG, Bellolio MF, Gilmore RM, et al. Pharmacologic elevation of blood pressure for acute brain ischemia. Neurocrit Care. 2008;8:259-61.

42. Muench E, Horn P, Bauhuf C, et al. Effects of hypervolemia and hypertension on regional cerebral blood flow, intracranial pressure, and brain tissue oxygenation after subarachnoid hemorrhage. Crit Care Med. 2007;35:1844-51. 